\title{
Low and decreasing vaccine effectiveness against influenza $A(H 3)$ in 2011/12 among vaccination target groups in Europe: results from the I-MOVE multicentre case-control study
}

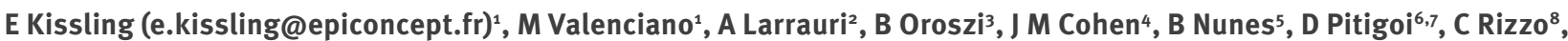

J Rebolledo 9,10 , I Paradowska-Stankiewicz ${ }^{11}$, S Jiménez-Jorge² ${ }^{2}$ J K Horváth ${ }^{3}$, I Daviaud 4 , R Guiomar5, G Necula ${ }^{6}$, A Bella ${ }^{8}$, J

O’Donnell', M Gtuchowska ${ }^{11}$, B C Ciancio ${ }^{12}$, A Nicoll ${ }^{12}$, A Moren ${ }^{1}$

1. EpiConcept, Paris, France

2. National Centre for Epidemiology, Instituto de Salud Carlos III, Madrid, Spain

3. Office of the Chief Medical Officer, Budapest, Hungary

4. GROG/Open Rome, Paris, France

5. Instituto Nacional de Saude Dr Ricardo Jorge, Lisbon, Portugal

6. Cantacuzino Institute, National Institute of Research - Development for Microbiology and Immunology, Bucharest, Romania

7. Universitatea de Medicina si Farmacie Carol Davila, Bucharest, Romania

8. National Centre for Epidemiology, Surveillance and Health Promotion, Istituto Superiore di Sanità, Roma, Italy

9. Health Protection Surveillance Centre, Dublin, Ireland

10. European Programme for Intervention Epidemiology Training (EPIET), European Centre for Disease Prevention and Control (ECDC), Stockholm, Sweden

11. National Institute for Public Health, Warsaw, Poland

12. European Centre for Disease Prevention and Control (ECDC), Stockholm, Sweden

Citation style for this article:

Kissling E, Valenciano M, Larrauri A, Oroszi B, Cohen JM, Nunes B, Pitigoi D, Rizzo C, Rebolledo J, Paradowska-Stankiewicz I, Jiménez-Jorge S, Horváth JK, Daviaud I, Guiomar R, Necula G, Bella A, O’Donnell J, Gtuchowska M, Ciancio BC, Nicoll A, Moren A. Low and decreasing vaccine effectiveness against influenza A(H3) in 2011/12 among vaccination target groups in Europe: results from the I-MOVE multicentre case-control study. Euro Surveill. 2013;18(5):pii=20390. Available online: http://www.eurosurveillance.org/ViewArticle.aspx?Articleld $=20390$

Within the Influenza Monitoring Vaccine Effectiveness in Europe (I-MOVE) project we conducted a multicentre case-control study in eight European Union (EU) Member States to estimate the 2011/12 influenza vaccine effectiveness against medically attended influenza-like illness (ILI) laboratory-confirmed as influenza $\mathrm{A}\left(\mathrm{H}_{3}\right)$ among the vaccination target groups. Practitioners systematically selected ILI / acute respiratory infection patients to swab within seven days of symptom onset. We restricted the study population to those meeting the EU ILI case definition and compared influenza $\mathrm{A}\left(\mathrm{H}_{3}\right)$ positive to influenza laboratory-negative patients. We used logistic regression with study site as fixed effect and calculated adjusted influenza vaccine effectiveness (IVE), controlling for potential confounders (age group, sex, month of symptom onset, chronic diseases and related hospitalisations, number of practitioner visits in the previous year). Adjusted IVE was $25 \%$ ( $95 \%$ confidence intervals (CI): -6 to 47$)$ among all ages $(n=1,014), 63 \%(95 \% \mathrm{Cl}: 26$ to 82) in adults aged between 15 and 59 years and $15 \%$ (95\% Cl: -33 to 46 ) among those aged 60 years and above. Adjusted IVE was $38 \%(95 \% \mathrm{Cl}:-8$ to 65$)$ in the early influenza season (up to week 6 of 2012) and $-1 \%(95 \% \mathrm{Cl}:-60$ to 37$)$ in the late phase. The results suggested a low adjusted IVE in 2011/12. The lower IVE in the late season could be due to virus changes through the season or waning immunity. Virological surveillance should be enhanced to quantify change over time and understand its relation with duration of immunological protection. Seasonal influenza vaccines should be improved to achieve acceptable levels of protection.

\section{Introduction}

Unlike the formulation of other vaccines, the formulation of seasonal influenza vaccines is reviewed annually by the World Health Organization (WHO) and frequently adapted to the constantly evolving nature of influenza viruses.

How the vaccine performs in target group populations cannot be anticipated by pre-authorisation efficacy trials in healthy young adults, immunogenicity studies or the relatedness of vaccine and circulating viruses. Field influenza vaccine effectiveness (IVE) studies provide essential additional information to advise stakeholders on the performance of the vaccine, to contribute to vaccine strain selection process and to inform when additional measures, such as antivirals, are needed given a low observed effectiveness early in the season.

In the European Union (EU) countries, the seasonal influenza vaccine is recommended annually for specific target groups, including those at risk of severe disease, the largest groups being older individuals (generally 60 or 65 years and above, depending on the country) and all those over six months of age with 
underlying medical conditions in the following categories: chronic respiratory and cardiovascular diseases, chronic metabolic disorders, chronic renal and hepatic diseases and immune system dysfunctions (congenital or acquired) [1].

In 2007, the European Centre for Disease Prevention and Control (ECDC) and a network of 18 public health institutes established the Influenza Monitoring Vaccine Effectiveness in Europe (I-MOVE) project which monitors IVE each season in the EU and the European Economic Area (EEA) [2]. Currently 20 public health institutes from the EU and EEA are part of the I-MOVE network, which is coordinated by EpiConcept under the umbrella of ECDC [3]. One component of I-MOVE is a multicentre case-control study, which has provided IVE estimates each season since the pilot season in 2008/09 [4-8]. All study sites follow a generic protocol [9].

During the pilot phase in the 2008/09 season, the pooled adjusted IVE estimates from the multicentre case-control study, restricted to individuals aged 65 years and above, suggested an overall IVE of $59.1 \%$ (95\% confidence intervals (Cl): 15.3 to $80.3 \%$ ). In the subsequent season 2009/10, an adjusted pandemic IVE of $71.9 \%$ ( $95 \% \mathrm{Cl}: 45.6$ to 85.5 ) among all age groups was estimated and in the 2010/11 season an adjusted IVE of $56.2 \%$ ( $95 \% \mathrm{Cl}: 34.3$ to 70.7 ) was calculated among the target group for vaccination $[4,5,7]$.

The aim was to provide overall and age-specific IVE estimates among what is defined as the target group for vaccination in these countries [10-17]. We restricted the analysis to influenza $A\left(\mathrm{H}_{3}\right)$, as this was the predominant strain during the season [18]. The 2011/12 seasonal influenza $A\left(\mathrm{H}_{3}\right)$ vaccine virus for the northern hemisphere was $A /$ Perth/16/2009 ( $\left.\mathrm{H}_{3} \mathrm{~N}_{2}\right)$-like virus.

\section{Methods}

The eight study sites included in the 2011/12 I-MOVE multicentre case-control study were based in France, Hungary, Ireland, Italy, Poland, Portugal, Romania and Spain. At each study site, practitioners already participating in the European Influenza Surveillance Network (EISN) were invited to take part in the study [19]. In addition, study sites in Hungary and Portugal invited practitioners outside the EISN network.

The study population consisted of non-institutionalised influenza-like-illness (ILI) patients without contraindications for vaccination who were swabbed within less than eight days after symptom onset. Practitioners carried out naso-pharyngeal swabbing and collected information from patients consulting for ILI or, for France only, for acute respiratory infection (ARI). Only patients adhering to the EU ILI case definition were included (sudden onset of symptoms and at least one of the following four systemic symptoms: fever or feverishness, malaise, headache, myalgia; and at least one of the following three respiratory symptoms: cough, sore throat, shortness of breath) [20]. In all study sites, practitioners swabbed all elderly (6o or 65 years old and older) consulting for ILI, except for France where a proportion of elderly consulting for ARI were systematically selected for swabbing. Practitioners systematically selected patients from other age groups to swab using statistical sampling, except for Romania, where all patients consulting for ILI were swabbed. Hungary restricted their study population to those aged 18 years and over.

All participants in the study gave oral or written consent, in adherence with country requirements for ethical approval at each study site. The study period began 15 days after the start of the respective 2011/12 seasonal influenza vaccination campaign in each country.

Practitioners used standardised country-specific questionnaires to collect information on ILI signs and symptoms, sex, age, seasonal influenza vaccination in the 2011/12 and 2010/11 seasons, pregnancy, chronic conditions (including obesity, as defined in the participating countries), number of hospitalisations for chronic conditions in the past 12 months, receipt of antivirals (Spain and France excluded), and number of general practitioner (GP) visits in the past 12 months. Study sites included a question on belonging to the target group for vaccination, apart from France and Portugal, where this information was gathered using information on age, chronic conditions, and pregnancy. In addition, information related to target groups for vaccination was gathered in Portugal on whether the patient was a health professional or carer and a co-habitant or carer of a patient at-risk aged less than six months.

Among ILI patients fulfilling the inclusion criteria, we defined a case of influenza as a study participant whose swab tested positive for influenza virus by reverse-transcription polymerase chain reaction (RT-PCR) or culture. We classified patients with swabs testing negative for influenza virus as controls.

Swabs were tested for influenza at the respective country's National Influenza Reference Laboratory. In France, Italy, and Spain, tests were also conducted in other laboratories participating in the National Influenza Sentinel Surveillance System. At all study sites a subset of isolates were genetically and/or antigenically characterised. Details of laboratory viral detection, typing, subtyping and variant analysis performed are described elsewhere [21].

We defined a person as vaccinated if they had received at least one dose of 2011/12 seasonal influenza vaccine more than 14 days prior to ILI/ARI symptom onset. All the others were classified as unvaccinated.

The eight study teams sent their data to EpiConcept, where they were pooled and analysed. We carried out an analysis restricted to the $A\left(\mathrm{H}_{3}\right)$ influenza type. We excluded controls presenting to the practitioner before the week of symptom onset of the first case and after 
the last case of influenza $\mathrm{A}\left(\mathrm{H}_{3}\right)$ in each country respectively. We restricted the study population to the target groups for vaccination. We compared the characteristics of cases and controls using chi-square tests, t-tests, Fisher's exact test or the Mann-Whitney test depending on the nature of the variable.

We used Cochran's Q-test and the 12 index to test the heterogeneity between study sites [22].
We estimated the pooled IVE as 1 minus the odds ratio $(O R)$ of being vaccinated in cases versus controls, using a one-stage method with study site as fixed effect in the model.

To estimate adjusted IVE, we used a logistic regression model including potential confounding factors: age (10year age bands), sex, presence of at least one chronic condition (including pregnancy and obesity), at least

\section{FIGURE 1}

Influenza-like illness / acute respiratory infection rates by week of symptom onset as reported by the national sentinel systems, I-MOVE multicentre case-control study, study sites in eight European Union countries, influenza season 2011/12
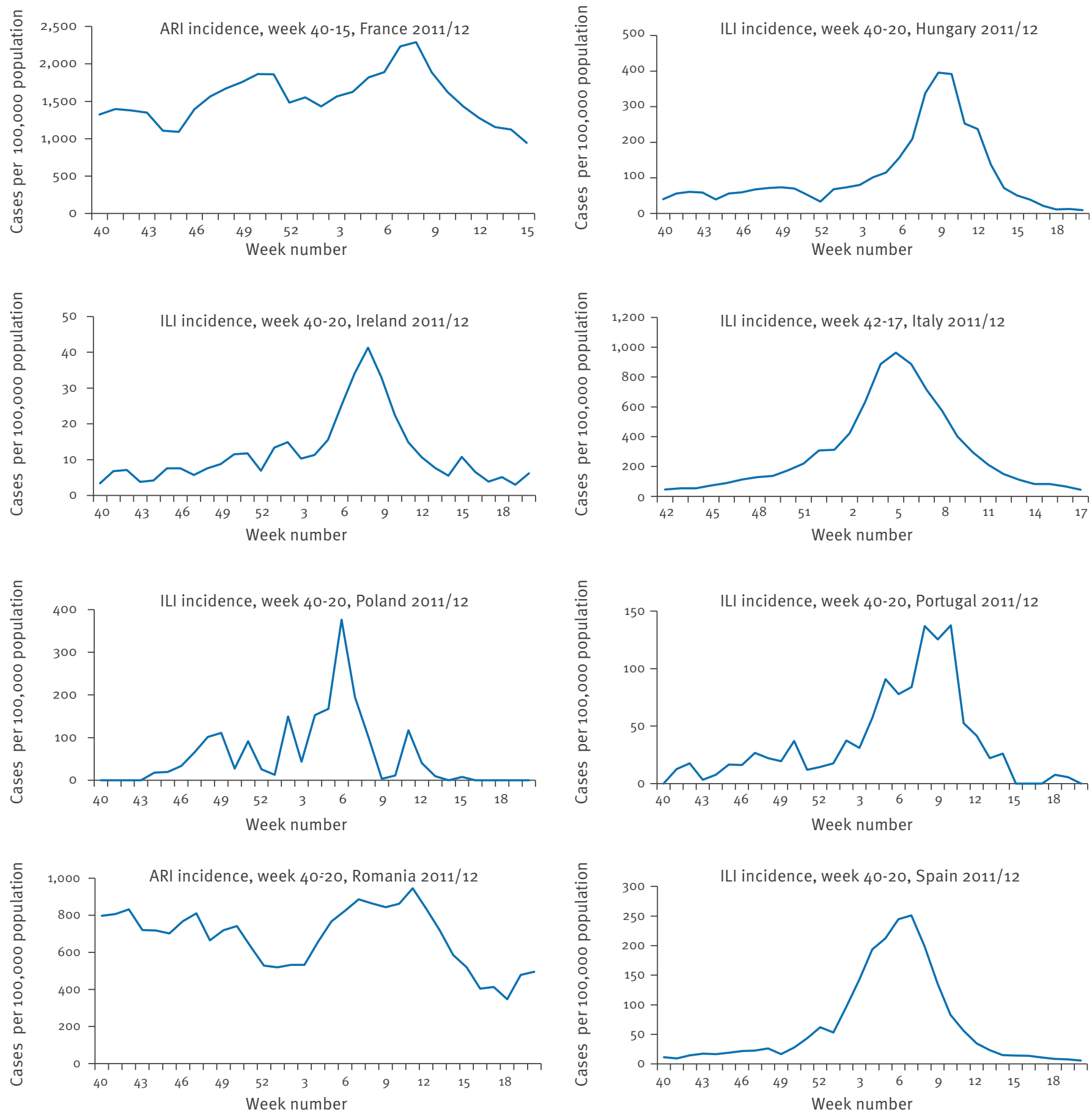

ARI: acute respiratory infection; ILI: influenza-like illness. 
one hospitalisation in the previous 12 months for the chronic condition, number of practitioner visits in the previous 12 months (0-1, 2-4 and $\geq 5$ visits) and month of symptom onset.

We stratified IVE into three age groups (0-14, 15-59 and 60 years and above). Since the influenza season started unusually late in Europe, we studied IVE in the early and late phase of the season and by time since vaccination [23]. The early and late phases of the influenza season were defined as up to and including week 6 of 2012 and from week 7 respectively, categories which allow for a similar sample size. In each of the two phases, we also calculated IVE by time since vaccination, with IVE estimates for symptom onset less than 93 days (around three months) since vaccination and 93 days or more since vaccination.

We conducted all statistical analysis using Stata version 12 (StataCorp. 2011. Stata Statistical Software: Release 12. College Station, TX: StataCorp LP).

\section{Results}

In the eight participating countries, influenza peaked at different times - from week 5 in Italy and Poland to week 10 in Portugal (Figure 1).

A total of 16 vaccines were used at the country study sites, of which four were adjuvanted. The start of the country-specific vaccination campaigns ranged between 12 September 2011 (Poland) and 15 December 2011 (certain regions in Romania). A total of 1,057 practitioners agreed to participate in the study of which 747
(71\%) recruited at least one patient, giving a total of 4,746 patients recruited (Table 1 ).

After exclusion of one individual who had received antivirals prior to swabbing, 21 individuals for whom laboratory results were missing, 10 individuals who received vaccination prior to the begin of the country's national vaccination campaign, 170 individuals who did not adhere to the EU ILI case definition, 19 individuals who were swabbed more than seven days after symptom onset and 163 individuals who presented before or after the week of onset of the first and last influenza case respectively, 4,362 individuals met the study inclusion criteria. Among those, 2,084 were cases, of which 1,764 were positive for influenza $A\left(H_{3}\right)(84.6 \%), 30$ were positive for influenza $A\left(H_{1} N_{1}\right)$ (1.4\%), 39 were influenza A unsubtypable (1.9\%) and 251 were positive for influenza B $(12.0 \%)$. As the analysis was restricted to the $\mathrm{A}\left(\mathrm{H}_{3}\right)$ subtype, the 320 individuals who had an influenza type other than $\mathrm{A}\left(\mathrm{H}_{3}\right)$ were excluded. As the study site in Poland reported no $\mathrm{A}\left(\mathrm{H}_{3}\right)$ cases, all controls from this study site were excluded from the analysis (a further 112 records). An additional 18 individuals who presented before and after the first and last case of influenza $\mathrm{A}\left(\mathrm{H}_{3}\right)$ respectively were excluded. This gave a total of 3,912 patients, of whom $1,033(26.4 \%)$ were part of the target group for vaccination (Figure 2 ).

We included 1,016 ILI patients without missing information on seasonal vaccination (12 patients) or other covariates (five patients) in the IVE complete case analysis: 437 cases and 579 controls. A further eight

\section{TABLE 1}

Participating practitioners and recruited influenza-like illness patients, by A(H3) influenza case-control status, vaccination status and study site, multicentre case-control study, study sites in eight European Union countries $^{\mathrm{a}}, 2011 / 12$

\begin{tabular}{|c|c|c|c|c|c|c|c|c|}
\hline \multirow[t]{2}{*}{ Study site } & \multirow[t]{2}{*}{$\begin{array}{l}\text { Number of } \\
\text { practitioners } \\
\text { participating } \\
\text { in the study }\end{array}$} & \multirow[t]{2}{*}{$\begin{array}{l}\text { Number of } \\
\text { practitioners } \\
\text { recruiting at } \\
\text { least one ILI } \\
\text { patient }^{b}\end{array}$} & \multirow[t]{2}{*}{$\begin{array}{l}\text { Number of } \\
\text { ILI patients }{ }^{\mathrm{b}} \\
\text { recruited by } \\
\text { practitioners }\end{array}$} & \multirow[t]{2}{*}{$\begin{array}{l}\text { Inclusion period } \\
\quad(\text { ISO weeks) }\end{array}$} & \multicolumn{2}{|c|}{$\begin{array}{l}\text { Number of ILI patients } \\
\text { positive for influenza } \\
\text { A(H3) and with known } \\
\text { vaccination status } \\
\text { included in the study }\end{array}$} & \multicolumn{2}{|c|}{$\begin{array}{l}\text { Number of ILI patients } \\
\text { included in the study } \\
\text { negative for any } \\
\text { influenza and with } \\
\text { known vaccination } \\
\text { status }^{\text {d }}\end{array}$} \\
\hline & & & & & Total & Vaccinated & Total & Vaccinated \\
\hline France & 499 & 319 & 1,264 & Week 52/2011-week 15/2012 & 75 & 30 & 84 & 34 \\
\hline Ireland & 29 & 16 & 137 & Week 48/2011-week 12/2012 & 12 & 7 & 9 & 6 \\
\hline Italy & 10 & 10 & 191 & Week 48/2011-week 10/2012 & 21 & 7 & 37 & 17 \\
\hline Poland & 35 & 22 & 170 & $\begin{array}{l}\text { Not included in analysis (no } \\
\text { influenza } A\left(\mathrm{H}_{3}\right) \text { cases) }\end{array}$ & 0 & NA & NA & NA \\
\hline Portugal & 59 & 35 & 352 & Week 51/2011-week 12/2012 & 59 & 15 & 77 & 35 \\
\hline Romania & 100 & 71 & 238 & Week 52/2011-week 14/2012 & 33 & 2 & 45 & 8 \\
\hline Total & 1,057 & 747 & 4,746 & - & 440 & 155 & 581 & 212 \\
\hline
\end{tabular}

ILI: Influenza-like illness; ISO: International Organization for Standardization. NA: not applicable

a France, Hungary, Ireland, Italy, Poland, Portugal, Romania, Spain

b ILI patients meeting the European Union case definition, swabbed less than eight days after onset of symptoms.

From 15 days after the start of the vaccination campaign; controls with an onset of symptoms in the weeks prior to the first influenza $\mathrm{A}\left(\mathrm{H}_{3}\right)$ case or after the last influenza $\mathrm{A}\left(\mathrm{H}_{3}\right)$ case were excluded.

d ILI patients in a target group for vaccination included in the study, after excluding those with missing information on laboratory results, vaccination status or date of vaccination. 
patients from France with imprecise vaccination dates were excluded in the analysis by time since vaccination.

The vaccination coverage in the studies was $35.9 \%$ $(n=367)$ among the target group for vaccination and varied by study site from $12.8 \%$ (Romania) to $61.9 \%$ (Ireland).

\section{FIGURE 2}

Flowchart of data exclusion for pooled analysis, I-MOVE multicentre case-control study, study sites in eight European Union countries, 2011/12

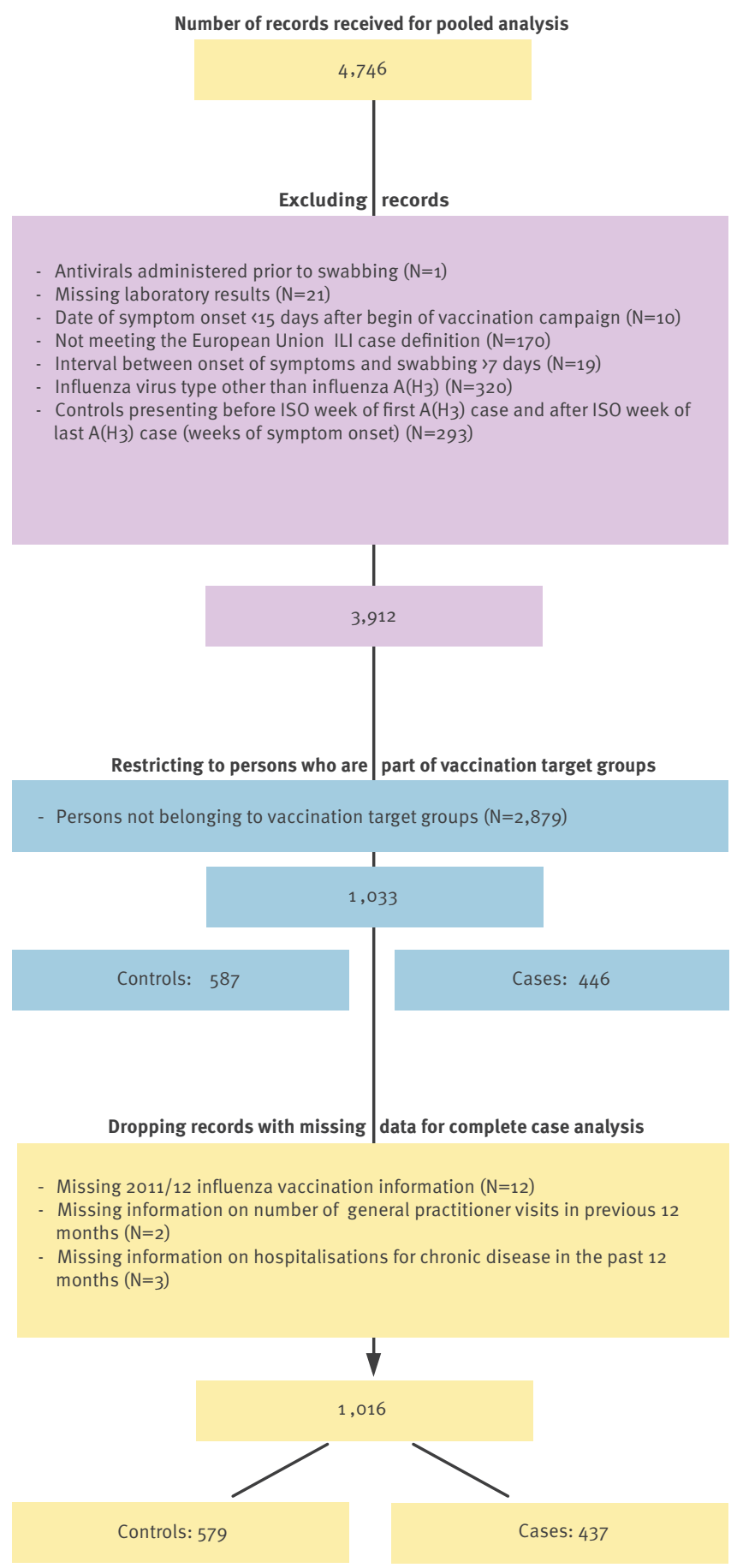

ILI: Influenza-like illness; ISO: International Organization for Standardization.
The median age was higher among cases (62.0 years; interquartile range (IQR): $37-70$ years) than among controls (58.0 years; IQR: 41-69 years) (Table 2).

The proportion of cases presenting with any of the following symptoms was higher than controls: fever, malaise, myalgia and cough. A greater proportion of controls than cases had heart disease or at least one chronic condition. A greater proportion of controls visited their practitioner five or more times in the previous 12 months. A greater proportion of cases were swabbed within three days of symptom onset, but this was not statistically significant to the $5 \%$ level. The delay between vaccination and symptom onset was shorter for controls (median: 88.5 days, IQR: 64-115 days) than for cases (median: 116.0 days, IQR: 95-131 days).

\section{FIGURE 3}

Pooled adjusted 2011/12 seasonal vaccine effectiveness against laboratory-confirmed influenza $\mathrm{A}(\mathrm{H} 3)$ cases in vaccination target groups, by time since vaccination, at study sites in seven European Union countries ${ }^{\mathrm{a}}$, week 46/2011-week 17/2012 ( $n=1,008)$

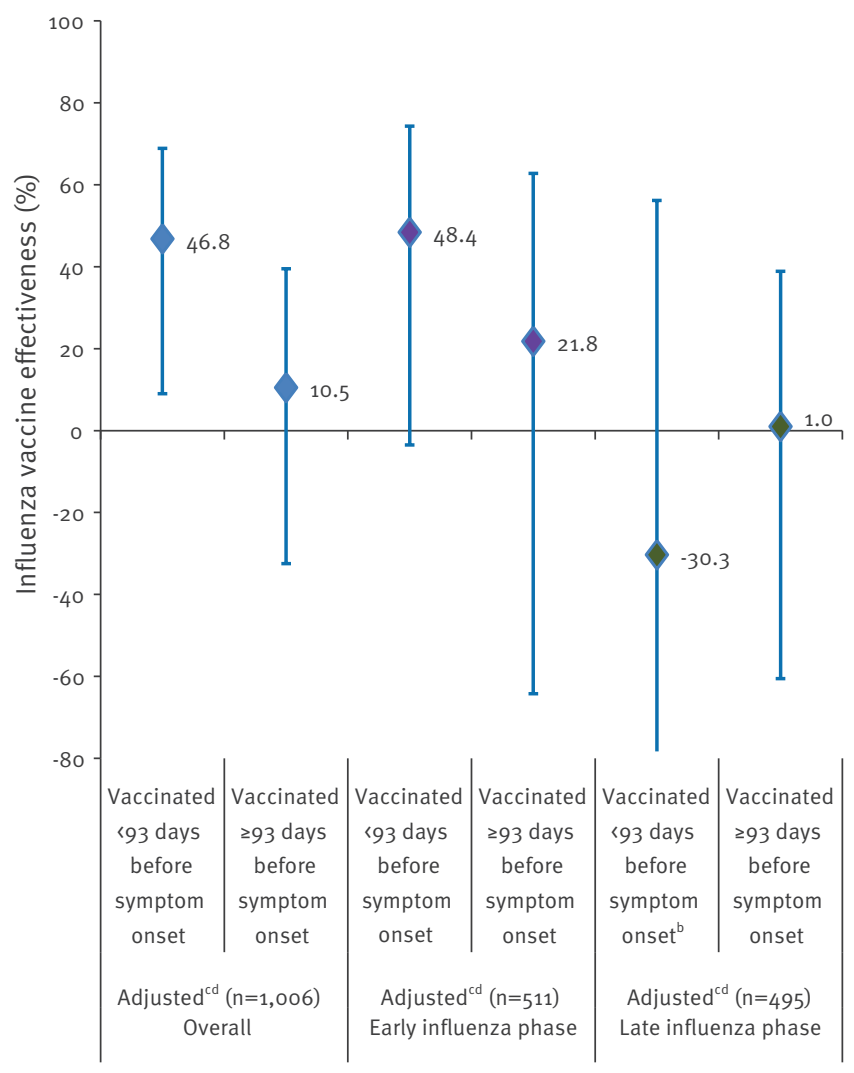

France, Hungary, Ireland, Italy, Portugal, Romania, Spain

b Lower boundary $95 \% \mathrm{Cl}:-288$.

Model adjusted for presence of at least one chronic disease, sex, at least one hospitalisation for chronic disease in the previous 12 months, age group, practitioner visits in the previous 12 months ( $0-1,2-4$ and $\geq 5$ visits), month of symptom onset and study site.

d November dropped due to no cases (two records dropped), eight records omitted from France, due to imprecise vaccination date. 
The $Q$ test $(p=0.142)$ and the 12 index $(37.6 \%)$ testing for heterogeneity between the individual crude IVE estimates of the seven study sites included, suggested low to medium statistical heterogeneity.

Crude IVE against $\mathrm{A}\left(\mathrm{H}_{3}\right)$ was $12.2 \%$ (95\% $\mathrm{Cl}:-17.2$ to 34.2 ) and the adjusted IVE was $24.8 \%$ (95\% Cl: -5.6 to 46.5) (Table 3). Due to small sample size, an adjusted IVE was not interpretable among the individuals under 15 years of age. Among those aged between 15 and 59 years, the adjusted IVE was $63.3 \%(95 \% \mathrm{Cl}: 25.9$ to 81.8 ) and $15.1 \%$ (95\% Cl: -33.1 to 45.9$)$ among those aged 60 years and over.
In the early phase of the season (week 46/2011 to week 6/2012) the adjusted IVE was $38.1 \%$ (95\% Cl: -7.9 to 64.5$)$ and in the late phase $-0.7 \%(95 \% \mathrm{Cl}:-59.8$ to 36.5). The adjusted IVE among persons with onset of symptoms less than three months since vaccination was $46.8 \%$ (95\% Cl: 9.0 to 68.9 ) and the IVE among persons with onset of symptoms three months or more since vaccination was $10.5 \%(95 \% \mathrm{Cl}:-32.5$ to 39.5$)$ (Figure 3).

When restricting to the early influenza phase, IVE among persons with onset of symptoms less than 93 days since vaccination was $48.4 \%$ ( $95 \% \mathrm{Cl}:-3.5$ to 74.3 ) and the IVE among persons with onset of symptoms

\section{TABLE 2}

Characteristics of $A(H 3)$ influenza cases $(n=446)$ and test-negative controls $(n=587)$ in vaccination target groups, multicentre case-control study, seven European Union countries ${ }^{\mathrm{a}}$, week 46/2011-week 17/2012

\begin{tabular}{|c|c|c|c|}
\hline Characteristic & $\begin{array}{c}\text { Number of } \mathrm{A}\left(\mathrm{H}_{3}\right) \\
\text { influenza cases/total } \\
n(\%)^{\mathrm{b}}\end{array}$ & $\begin{array}{c}\text { Number of test- } \\
\text { negative } \\
\text { controls/total } \\
n(\%)^{\mathrm{b}}\end{array}$ & $p$ value \\
\hline Median age & 62.0 & 58.0 & $0.008^{c}$ \\
\hline \multicolumn{4}{|l|}{ Age group (years) } \\
\hline $0-4$ & $15 / 446(3.4)$ & $24 / 587(4.1)$ & $0.05^{d}$ \\
\hline 5-14 & $23 / 446(5.2)$ & $19 / 587(3.2)$ & - \\
\hline $15-59$ & $164 / 446(36.8)$ & $272 / 587(46.3)$ & - \\
\hline$\geq 60$ & $244 / 446(54.7)$ & $272 / 587(46.3)$ & - \\
\hline Female sex & $242 / 446(54.3)$ & $357 / 587(60.3)$ & $0.056^{d}$ \\
\hline \multicolumn{4}{|l|}{ Symptoms } \\
\hline Fever & 425/444 (95.7) & $523 / 584(89.6)$ & $<0.001^{\mathrm{d}}$ \\
\hline Malaise & $349 / 365(95.6)$ & 457/498 (91.8) & $0.026^{d}$ \\
\hline Myalgia & $394 / 444(88.7)$ & $465 / 583(79.8)$ & $<0.001^{\mathrm{d}}$ \\
\hline Cough & $425 / 445(95.5)$ & $525 / 587(89.4)$ & $<0.001^{\mathrm{d}}$ \\
\hline Sore throat & $318 / 441(72.1)$ & $451 / 587(76.8)$ & $0.095^{\mathrm{d}}$ \\
\hline Shortness of breath & $96 / 439$ (21.9) & $139 / 580(24.0)$ & $0.453^{d}$ \\
\hline \multicolumn{4}{|l|}{ Days between onset of symptoms and swabbing } \\
\hline$<4$ & $399 / 446(89.5)$ & $508 / 587(86.5)$ & $0.179^{d}$ \\
\hline$\geq 4$ & $47 / 446(10.5)$ & $79 / 587(13.5)$ & - \\
\hline 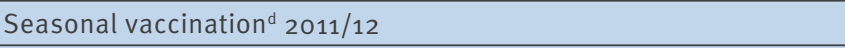 & $155 / 440(35.2)$ & $212 / 581(36.5)$ & $0.693^{d}$ \\
\hline Seasonal vaccination $2010 / 11$ & $147 / 441(33.3)$ & $213 / 584(37.0)$ & $0.236^{d}$ \\
\hline Obesity $^{f}$ & $56 / 446(12.6)$ & $97 / 587(16.5)$ & $0.078^{\mathrm{d}}$ \\
\hline Heart diseases & $99 / 446(22.2)$ & $194 / 587(33.0)$ & $<0.001^{\mathrm{d}}$ \\
\hline At least one chronic condition (including pregnancy) & $295 / 446(66.1)$ & $467 / 587(79.6)$ & $<0.001$ \\
\hline \multicolumn{4}{|l|}{ Smoker } \\
\hline Current & $44 / 365(12.1)$ & $75 / 496(15.1)$ & $0.176^{d}$ \\
\hline Former & $60 / 365(16.4)$ & $96 / 496(19.4)$ & - \\
\hline Never & $261 / 365(71.5)$ & $325 / 496(65.5)$ & - \\
\hline Five or more practitioner visits in the previous 12 months & $224 / 445(50.3)$ & $347 / 586(59.2)$ & $0.005^{c}$ \\
\hline Any hospitalisation in the previous 12 months for chronic diseases & $27 / 444(6.1)$ & $50 / 585(8.5)$ & $0.152^{\mathrm{c}}$ \\
\hline Median number of days from vaccination ${ }^{\mathrm{e}}$ to onset of ILI symptoms & 116.0 & 88.5 & $<0.001^{b}$ \\
\hline
\end{tabular}

ILI: influenza-like illness.

a France, Hungary, Ireland, Italy, Portugal, Romania, Spain

b Unless otherwise indicated.

Non parametric test of the median.

dwo-sided Fisher's exact test.

e Vaccination more than 14 days before onset of influenza-like illness symptoms.

As defined in the respective countries. 
93 days or more since vaccination was $21.8 \%$ (95\% Cl: -64.2 to 62.8$)$. When restricting to the late phase, IVE among persons with onset of symptoms less than 93 days since vaccination was $-30.3 \%(95 \% \mathrm{Cl}:-287.7$ to 56.2) and the IVE among persons with onset of symptoms more than 93 days since vaccination was $1.0 \%$ (95\% Cl: -60.5 to 38.9) (Figure 3).

\section{Discussion}

The overall adjusted pooled IVE estimates against influenza $\mathrm{A}\left(\mathrm{H}_{3}\right)$ from the multicentre case-control study in Europe among those targeted for vaccination was $24.8 \%$, ranging between $15.1 \%$ in the elderly and $63.3 \%$ in persons aged between 15 and 59 years. This suggests a low adjusted IVE against medically attended $\mathrm{A}\left(\mathrm{H}_{3}\right)$ influenza among the target population except among younger adults.

The $\mathrm{A}\left(\mathrm{H}_{3}\right)$ strain was also predominant during the 2008/09 season, the I-MOVE pilot season. In that season, persons aged 65 and above had an IVE of $56.4 \%$ (95\% Cl: -0.2 to 81.0) against $\mathrm{A}\left(\mathrm{H}_{3}\right)$ [5]. We observed a lower IVE in the 2011/12 $\mathrm{A}\left(\mathrm{H}_{3}\right)$ dominated season with an IVE of $15.1 \%$ in those aged 60 years and above and an IVE of $12.4 \%$ in those aged 65 years and above.

The strength of this study lies in its multicentre nature, enabling recruitment of a large sample size of participants across the EU. It is possible to restrict to the target group for vaccination and to stratify further by influenza type and age. Study sites adhere to a common protocol and carry out systematic sampling. They also collect information on potentially important positive and negative confounders. In addition, data quality is very high with only $1.7 \%(n=17 / 1033)$ of records with missing data.

Due to the observational nature of this study, we cannot exclude biases. We used a test-negative design, which is subject to the usual selection biases particularly for the control group. Study participants are selected according to a systematic sampling procedure by practitioners, who are blinded to the case and control status of the patients. This should minimise selection bias.

As I-MOVE is based on existing sentinel networks, GPs recruited patients according to the case definitions used in their network: the EU ILI case definition or the ARI case definition. As the ARI case definition is a more sensitive case definition than the EU ILI one, we could restrict the analysis to patients meeting the EU ILI case definition for all patients included in the study.

The test-negative design is a commonly used, but not validated study design [24-32]. Using test-negative controls is considered to adjust for healthcare-seeking behaviour more so than if community controls were selected, as vaccination coverage varies by healthcareseeking behaviour [34,35]. In addition, the covariate 'number of GP visits in the past 12 months' may adjust further for healthcare-seeking behaviour. Despite this adjustment, it is still debatable if test-negative controls properly reflect the vaccine coverage of the source population for cases [33].

While a higher proportion of controls visited their GP more frequently and had a chronic condition than cases,

\section{TABLE 3}

Pooled crude and adjusted 2011/12 seasonal influenza vaccine effectiveness against laboratory-confirmed A(H3) influenza in vaccination target groups, at study sites in seven European Union countries ${ }^{a}$, week 46/2011-week 17/2012 (patients with complete information, $\mathrm{n}=1,016$ )

\begin{tabular}{|c|c|c|c|c|}
\hline & & Number & $\begin{array}{l}\text { Influenza vaccine } \\
\text { effectiveness in \% }\end{array}$ & $\begin{array}{l}95 \% \text { confidence } \\
\text { intervals }\end{array}$ \\
\hline \multirow{2}{*}{ Overall } & Crude $^{b}$ & 1,016 & 12.2 & -17.2 to 34.2 \\
\hline & Adjusted ${ }^{c, d}$ & 1,014 & 24.8 & -5.6 to 46.5 \\
\hline \multirow{2}{*}{ «15 years } & Crude $^{\mathrm{b}}$ & 78 & 19.4 & -170.1 to 75.9 \\
\hline & Adjusted ${ }^{c}$ & - & - & - \\
\hline \multirow{2}{*}{$15-59$ years } & Crude $^{\mathrm{b}}$ & 431 & $59 \cdot 3$ & 24.4 to 78.1 \\
\hline & Adjusted $^{c}$ & 431 & 63.3 & 25.9 to 81.8 \\
\hline \multirow{2}{*}{60 years and above } & Crude $^{\mathrm{b}}$ & 505 & 6.4 & -40.7 to 37.7 \\
\hline & Adjusted ${ }^{c, d}$ & 503 & 15.1 & -33.1 to 45.9 \\
\hline \multirow{2}{*}{$\begin{array}{l}\text { First influenza phase } \\
\text { (week 46/2011 to week 6/2012) }\end{array}$} & Crude $^{b}$ & 515 & 38.2 & 2.8 to 60.7 \\
\hline & Adjusted ${ }^{c, d}$ & 513 & 38.1 & -7.9 to 64.5 \\
\hline \multirow{2}{*}{$\begin{array}{l}\text { Second influenza phase } \\
\text { (week 7/2012 to week 17/2012) }\end{array}$} & Crude $^{b}$ & 501 & -17.6 & -75.9 to 21.4 \\
\hline & Adjusted ${ }^{c, d}$ & 501 & -0.7 & -59.8 to 36.5 \\
\hline
\end{tabular}

a France, Hungary, Ireland, Italy, Portugal, Romania, Spain

b Study site included in the model as fixed effect.

Model adjusted for presence of at least one chronic disease, sex, at least one hospitalisation for chronic disease in the previous 12 months, age group, practitioners' visits in the previous 12 months (0-1, 2-4 and $\geq 5$ visits), month of symptom onset and study site.

d November dropped due to no cases (two records dropped). 
these variables were not strong confounders $(-2 \%$ and $1 \%$ relative difference of IVE between model containing and not containing these confounders respectively). The main confounder was age group, changing the IVE of the adjusted model by $11 \%$.

We cannot exclude residual confounding, either by unmeasured confounders or by use of broad categories within given confounders. However, we used 10-year age bands to reduce residual confounding by age. While we used month of symptom onset as a covariate, the IVE differs only little if using week of symptom onset ( $24.8 \%$ compared to $23.4 \%$ for overall IVE).

We included patients who were swabbed within seven days of symptom onset and we observed that a higher proportion of controls were swabbed more than three days after symptom onset than cases, although the difference is not statistically significant. The probability of influenza detection decreases with time between onset and swabbing, although the rate of decrease may vary by patient characteristics [35-38]. It is possible that some misclassification bias is introduced by including false negative controls through including patients with a greater delay between onset of symptoms and swabbing. However the difference is small if we compare our results to an analysis restricting the study population to persons swabbed three days or fewer since symptom onset ( $24.8 \%$ compared to $22.8 \%$ for overall IVE).

Our study is limited by a small sample size for the stratified analyses. Therefore precise estimates were not always possible, particularly among the youngest age group, who are often the least numerous target group for vaccination. Estimates by influenza phase and by time since vaccination are also limited by the small sample size and although point estimates differ, confidence intervals overlap.

The majority of countries participating in this study used both adjuvanted and non-adjuvanted influenza vaccines. The different vaccine types were used in different subpopulations. With the data collected for this study, it was not possible to identify the target groups to enable an estimate by vaccine type.

IVE estimates arising from the total population were lower than the estimates from the target group for vaccination, e.g. overall adjusted IVE of $10.9 \%$ (95\% $\mathrm{Cl}$ : -16.2 to 31.7 ) among the total population (data not shown), compared to $24.8 \%(95 \% \mathrm{Cl}:-5.6$ to 46.5 ) among the target group for vaccination. We believe that the target group for vaccination is a more homogeneous study population in relation to vaccination, the main exposure of interest, as study participants belonging to the target group for vaccination are likely to have a more equal access to vaccination than the total population.

One limitation of restricting to this population is that it is identified through the practitioner questionnaires, which did not collect information on target group homogeneously across study sites. In particular information on healthy persons with professions targeted for vaccination may have been omitted from some countries. Despite these limitations, we believe that our study suggests a low adjusted IVE against medically attended $\mathrm{A}\left(\mathrm{H}_{3}\right)$ influenza among the target population except for among young adults in the 2011/12 influenza season.

The lower IVE observed this season compared to the previous $\mathrm{A}\left(\mathrm{H}_{3}\right)$ dominated season (2008/09) may be due to changes in circulating viruses and hence suboptimal antigenic match between the 2011/12 vaccine and circulating strains. WHO and the Community Network of Reference Laboratories (CNRL) report northern hemisphere circulating $A\left(\mathrm{H}_{3} \mathrm{~N}_{2}\right)$ viruses being genetically and antigenically distinguishable from the $A$ / Perth/16/2009 vaccine strain and being more related to A/Victoria/361/2011-like reference viruses, differences which may have increased along the season $[18,39]$. This virological change could have contributed to the lower IVE in the latter part of the season.

As the 2011/12 influenza season was a late season, persons presenting with influenza had a long delay between onset of symptoms and the vaccination, as campaigns were carried out in the autumn of 2011. The observed fall in IVE may also be due in part to waning of the immunity induced by the vaccine, perhaps markedly so in older people [40-43]. Persons vaccinated less than 93 days before symptom onset showed a higher IVE than persons vaccinated 93 days or more before symptom onset. However, persons vaccinated 93 days or more before symptom onset were more likely to present later in the season, co-temporal with the emergence of antigenically drifted influenza viruses. To disentangle the possible effects of waning immunity and antigenic drift, we looked at IVE by early and late influenza phase. In the early influenza phase IVE was higher among persons vaccinated less than 93 days before symptom onset compared to persons vaccinated 93 days or more before symptom onset. This was not the case in the late influenza phase, where we may expect a greater effect of antigenic drift on the IVE estimates. This suggests the waning immunity hypothesis may be plausible.

In conclusion, the I-MOVE multicentre case-control study suggests a low IVE against medically attended $\mathrm{A}\left(\mathrm{H}_{3}\right)$ influenza in the $2011 / 12$ season. The I-MOVE multicentre case control study provides high quality and rapid IVE estimates and should supplement the virological information that informs the WHO recommendations on vaccine strain selection $[6,8]$. It is difficult to disentangle the respective roles of changes in the circulating viruses, possible waning immunity and otherwise imperfect vaccine. Further virological studies are needed on an annual basis quantifying drift over time as well as large epidemiological studies by time since vaccination with several delay categories to 
fully understand these potentially important issues. Production of an improved seasonal influenza vaccine with greater effectiveness should be given a high priority.

\section{Acknowledgements}

The European Centre for Disease Prevention and Control (ECDC) -funded the individual I-MOVE case-control studies in 2011/12 and funded the I-MOVE pooled analysis.

We are grateful to all patients, practitioners and epidemiologists from the eight study sites who actively participated in the study. France: Isidore Grog (collective name of the Réseau des GROG network); Sylvie van der Werf, Bruno Lina, Martine Valette, Vincent Enouf, Dominique Rousset, National Reference Centre for Influenza virus France North and South; Astrid Vabret, Françoise Stoll Keller, Geneviève Giraudeau, Hervé Fleury, Laurent Andreoletti, Pierre Pothier, associated hospital laboratories; Marion Quesne, Françoise Barat, William Ouadi, coordination team; Hungary: Marta Melles, general director of the National Center for Epidemiology; Monika Rózsa and staff of the Influenza Virus Laboratory, National Center for Epidemiology, Budapest; Saverio Caini, Department of Infectious Disease Epidemiology, National Center for Epidemiology, Budapest, Hungary and European Programme for Intervention Epidemiology Training (EPIET), ECDC, Stockholm, Sweden; Ireland: Suzanne Cotter, Lisa Domegan, Darina O’Flanagan, Aoibheann O Malley, Health Protection Surveillance Centre, Dublin; Suzie Coughlan, Joanne Moran, Grainne Tuite, Allison Waters, National Virus Reference Laboratory; Claire Collins, Michael Joyce, Irish Colleague of General Practitioners; Italy: Maria Cristina Rota, Silvia Declich, National Center for Epidemiology, Surveillance and Health Promotion, Istituto Superiore di Sanità, Rome; Simona Puzelli, Isabella Donatelli, National Influenza Centre, Rome; Enrico Volpe, Piero Borgia, Laziosanita' Agenzia di Sanita' Pubblica, Lazio Region; Roberto Rangoni, Alba Carola Finarelli, Regional Health Autorities, Emilia-Romagna Region; Maria Luisa Tanzi, Regional Reference Laboratory EmiliaRomagna; Giovanni Delogu, Regional Reference Laboratory, Lazio; Poland: Lidia Brydak and Agnieszka Kosek-Woźniak.

Thanks to epidemiologists, virologists, general practitioners and other person who were engaged in conducting I-MOVE project; Portugal: Ausenda Machado, Inês Batista, Carlos Matias Dias, José Marinho Falcão (retired), Department of Epidemiology, Instituto Nacional de Saúde Dr Ricardo Jorge, Lisbon; Paulo Gonçalves, Patricia Conde e Pedro Pechirra, Department of Infeccious Diseases, Instituto Nacional de Saúde Dr Ricardo Jorge, Lisbon; Rede Médicos Sentinela; Associação Portuguesa de Medicina Geral e Familiar [Portuguese association of general practitioners]; Romania: Viorel Alexandrescu, Alina Elena Ivanciuc, George Necula, Maria Elena Mihai and laboratory technical staff, Cantacuzino National Institute of Research-Development for Microbiology and Immunology, Bucharest; Adriana Pistol, Rodica Popescu, National Centre for Surveillance and Control of Communicable Diseases, Bucharest; epidemiologists from sentinel Public Health Directorates Constanta, Dolj, Iasi, Maramures, Calarasi, Prahova, Mures, Tulcea, Galati, Bihor, Sibiu; Spain: Salvador de Mateo, National Centre of Epidemiology, Instituto de Salud Carlos III; Inmaculada Casas and Francisco Pozo, National Influenza CentreMadrid, Instituto de Salud Carlos III; Jesús Castilla and Manuel García Cenoz, Instituto de Salud Pública de Navarra, Navarra; El CIBER de Epidemiología y Salud Pública; Virtudes Gallardo and Esteban Pérez, Servicio de Epidemiología y Salud Laboral. Secretaría General de Salud Pública y Participación, Consejería de Salud de Andalucía; Carolina Rodriguez and Tomás Vega, Dirección General de Salud Pública e Investigación, Desarrollo e Innovación, Consejería de Sanidad de Castilla y León; Carmen Quiñones and Eva Martinez, Servicio de Epidemiología, Subdirección de Salud Pública de La Rioja; Jaume Giménez and Juana M. Vanrell, Servicio de Epidemiología, Dirección General de Salut Pública, Baleares, Palma de Mallorca; CIBERESP; Daniel Castrillejo, Servicio de Epidemiología, Dirección General de Sanidad y Consumo, Consejería de Bienestar Social y Sanidad, Ciudad Autónoma de Melilla; Julián M. Ramos and Maria C. Serrano, Dirección General de Salud Pública, Servicio Extremeño de Salud, Junta de Extremadura.

Many thanks also to EpiConcept colleagues for their contributions: M. Rondy, C. Savulescu.

\section{References}

1. Mereckiene J, Cotter S, D’Ancona F, Giambi C, Nicoll A, Levy Bruhl D, et al. Differences in national influenza vaccination policies across the European Union, Norway and Iceland 2008-2009. Euro Surveill. 2010;15(44). pii=19700. Available from: http://www.eurosurveillance.org/ViewArticle. aspx?Articleld $=19700$

2. Valenciano M, Ciancio B, Moren A. First steps in the design of a system to monitor vaccine effectiveness during seasonal and pandemic influenza in EU/EEA Member States. Euro Surveill. 2008;13(43). pii=19015. Available from: http://www. eurosurveillance.org/ViewArticle.aspx?Articleld=19015

3. I-MOVE in Europe. I-MOVE in Europe. [Accessed 1 Aug 2012]. Available from: https://sites.google.com/site/epiflu/

4. Kissling E, Valenciano M, Falcao J, Larrauri A, Widgren K, Pitigoi D, et al. "I-MOVE" towards monitoring seasonal and pandemic influenza vaccine effectiveness: lessons learnt from a pilot multi-centric case-control study in Europe, 2008-9. Euro Surveill. 2009;14(44). pii=19388. Available from: http://www. eurosurveillance.org/ViewArticle.aspx?Articleld=19388

5. Valenciano M, Kissling E, Cohen J-M, Oroszi B, Barret A-S, Rizzo C, et al. Estimates of pandemic influenza vaccine effectiveness in Europe, 2009-2010: results of Influenza Monitoring Vaccine Effectiveness in Europe (I-MOVE) multicentre case-control study. PLoS Med. 2011;8(1):e1000388.

6. Kissling E, Valenciano M. Early estimates of seasonal influenza vaccine effectiveness in Europe, 2010/11: I-MOVE, a multicentre case-control study. Euro Surveill. 2011;16(11). $\mathrm{pii}=20146$. Available from: http://www.eurosurveillance.org/ ViewArticle.aspx?Articleld $=19818$

7. Kissling E, Valenciano M, Cohen JM, Oroszi B, Barret A-S, Rizzo C, et al. I-MOVE multi-centre case control study 2010 11: overall and stratified estimates of influenza vaccine effectiveness in Europe. PLoS ONE. 2011;6(11):e27622.

8. Kissling $E$, Valenciano $M$. Early estimates of seasonal influenza vaccine effectiveness in Europe among target groups for vaccination: results from the l-MOVE multicentre casecontrol study, 2011/12. Euro Surveill. 2012;17(15). pii=20146. Available from: http://www.eurosurveillance.org/ViewArticle. aspx?Articleld $=20146$

9. European Centre for Disease Prevention and Control (ECDC). Protocol for case-control studies to measure influenza vaccin effectiveness in the European Union and European Economic Area Member States. Stockholm:ECDC; 2009. Available from: http://ecdc.europa.eu/en/publications/publications/0907_ ted_influenza_ah1n1_measuring_influenza_vaccine_ effectiveness_protocol_case_control_studies.pdf

10. Orszagos Epidemiológiai Központ (OEK). Az Országos Epidemiológiai Központ módszertani level a 2011. évi védõoltásokról [The National Centre for Epidemiology methodological letter of the year 2011 on vaccinations]. Epinfo 2011;18. 21 Feb 2011. Hungarian. Available from: http://www. oek.hu/oek.web?nid=444\& $\mathrm{pid}=1$

11. Institut de Veille Sanitaire (InVS) Le calendrier vaccinal et les recommandations vaccinales 201 selon l'avis du Haut Conseil de la Santé Publique. [2011 vaccination schedule and recommendations from the Haut Conseil de la Santé Publique in France]. BEH 10-11/2011 p. 103-20. French. Available from: http://www.invs.sante.fr/content/download/4393/28810/ version/4/file/beh_10_11_2011.pdf

12. Ministerio de Sanidad, Servicios Sociales e Igualdad (MSPS). Prevención de la gripe. Vacunación antigripal [Influenza prevention. Recommendations for influenza vaccination]. [Accessed Jul 4 2012]. Spanish. Available from: http://www. msps.es/ciudadanos/enfLesiones/enfTransmisibles/gripe/ gripe.htm\#prevencion

13. Ministerio della Salute. Prevenzione e controllo dell'influenza: raccomandazioni per la stagione 2011-2012. [Prevention 
and control of influenza: recommendations for the season 2011-2012]. Roma: Ministero della Salute; 2012. Italian. Available from: http://www.normativasanitaria.it/normsanpdf/0000/39451_1.pdf

14. Metodologia de supraveghere a gripei, infectiilor acute respiratorii şi SARI pentru sezonul 2011-2012. [Methodology of surveillance of influenza, acute respiratory infections and SARI, season 2011-2012] Bucarest: National Centre for Surveillance and Control of Communicable Diseases; 2012. Romanian. Available from: http://www.insp.gov. ro/cnscbt/index.php?option=com_docman\&task $=$ doc download\&gid=286\&Itemid $=10$

15. Vacinaçao contra a gripe com a vacina trivalente na época 2011/2012 - Alargamento dos groupos de risco para vacinaçao gratuita. [Influenza vaccination with the trivalent vaccine in the season 2011/2012 - Extension of risk groups for free vaccinations] Lisbon: Directorate General of Health; Sep 2011. Portuguese. Available from: http://www.dgs.pt/ms/2/default. aspx?id=5509

16. Program Szczepień Ochronnych na rok 2012. [Immunisation Programme for 2012] Warsaw: Chief Sanitary Inspectorate; 2011. Polish. Available from: http://www.pis.gov.pl/userfiles/ file/Departament $\% 20$ EP/szczepienia/zal_szczep $\% 20 P S 0 \% 20$ 2012.pdf

17. Target groups for seasonal influenza vaccine $2011 / 2012$ - Ireland. Dublin: Health Protection Surveillance Centre; 2011. Available from: . http://www.immunisation. ie/en/HealthcareProfessionals/Correspondence/ PDFFile_16872_en.pdf

18. European Centre for Disease Control and Prevention (ECDC). Community Network of Reference Laboratories (CNRL) for Human Influenza in Europe. Influenza virus characterisation, summary Europe, June 2012 Stockholm:ECDC; 2012. Available from: http://www.ecdc.europa.eu/en/publications/ Publications/Influenza-visus-characterisation-June-2012.pdf

19. European Centre for Disease Control and Prevention (ECDC). European Influenza Surveillance Network (EISN). [Accessed 5 Jul 2012]. Available from: http://www.ecdc.europa.eu/en/ activities/surveillance/eisn/pages/index.aspx

20. European Commission. Commission Decision 2009/363/EC of 30 April 2009 amending Decision 2002/253/EC laying down case definitions for reporting communicable diseases to the Community network under Decision No 2119/98/EC of the European Parliament and of the Council. OJ L 110, 1.5.2009 p. 58. . Available from: http://eur-lex.europa.eu/LexUriServ/ LexUriServ.do?uri=0J:L:2009:110:0058:0059:EN:PDF

21. European Centre for Disease Control and Prevention (ECDC). Laboratory surveillance of influenza: Table [Accessed 5 Jul 2012]. Available from: http://www.ecdc.europa.eu/en/ activities/surveillance/EISN/laboratory_network/Pages/ laboratory_surveillance_influenza.aspx

22. Huedo-Medina TB, Sánchez-Meca J, Marín-Martínez F, Botella J. Assessing heterogeneity in meta-analysis: Q statistic or 12 index? Psychol Methods. 2006 Jun;11(2):193-206.

23. European Centre for Disease Control and Prevention (ECDC). Weekly Influenza Surveillance Overview (WISO). Stockholm:ECDC; 2012 [Accessed 4 Jul 2012]. Available from: http://ecdc.europa.eu/en/publications/surveillance_reports/ influenza/Pages/weekly_influenza_surveillance_overview. aspx

24. Cheng AC, Kotsimbos T, Kelly HA, Irving LB, Bowler SD, Brown $\mathrm{SG}$, et al. Effectiveness of $\mathrm{H}_{1} \mathrm{~N}_{1} / 09$ monovalent and trivalent influenza vaccines against hospitalization with laboratoryconfirmed $\mathrm{H}_{1} \mathrm{~N}_{1} / 09$ influenza in Australia: a test-negative case control study. Vaccine. 2011;29(43):7320-5.

25. Hellenbrand W, Jorgensen P, Schweiger B, Falkenhorst G, Nachtnebel M, Greutélaers B, et al. Prospective hospital-based case-control study to assess the effectiveness of pandemic influenza $A\left(\mathrm{H}_{1} \mathrm{~N}_{1}\right)$ pdmog vaccination and risk factors for hospitalization in 2009-2010 using matched hospital and testnegative controls. BMC Infectious Dis. 2012;12(1):127.

26. Belongia EA, Kieke BA, Donahue JG, Coleman LA, Irving SA, Meece JK, et al. Influenza vaccine effectiveness in Wisconsin during the 2007-08 season: comparison of interim and final results. Vaccine. 2011;29(38):6558-63.

27. Andrews N, Waight P, Yung C-F, Miller E. Age-specific effectiveness of an oil-in-water adjuvanted pandemic $\left(\mathrm{H}_{1} \mathrm{~N}_{1}\right)$ 2009 vaccine against confirmed infection in high risk groups in England. J Infect Dis. 2011;203(1):32-9.

28. Caviness AC, Demmler GJ, Selwyn BJ. Clinical and laboratory features of neonatal herpes simplex virus infection: a casecontrol study. Pediatr Infect Dis J. 2008;27(5):425-30.

29. Skowronski DM, De Serres G, Dickinson J, Petric M, Mak $A$, Fonseca K, et al. Component-specific effectiveness of trivalent influenza vaccine as monitored through a sentinel surveillance network in Canada, 2006-2007. J Infect Dis. 2009;199(2):168-79.

30. Castilla J, Beristain X, Martínez-Artola V, Navascués A, García Cenoz M, Alvarez N, et al. Effectiveness of rotavirus vaccines in preventing cases and hospitalizations due to rotavirus gastroenteritis in Navarre, Spain. Vaccine. 2012;30(3):539-43.

31. Fleming DM, Andrews NJ, Ellis JS, Bermingham A, Sebastianpillai P, Elliot AJ, et al. Estimating influenza vaccine effectiveness using routinely collected laboratory data. J Epidemiol Community Health. 2010;64(12):1062-7.

32. Benowitz I, Esposito DB, Gracey KD, Shapiro ED, Vázquez $M$. Influenza vaccine given to pregnant women reduces hospitalization due to influenza in their infants. Clin Infect Dis. 2010;51(12):1355-61.

33. Valenciano M, Kissling E, Ciancio BC, Moren A. Study designs for timely estimation of influenza vaccine effectiveness using European sentinel practitioner networks. Vaccine. 2010;28(46):7381-8.

34. Belongia EA, Kieke BA, Donahue JG, Greenlee RT, Balish $A$, Foust $A$, et al. Effectiveness of inactivated influenza vaccines varied substantially with antigenic match from the 2004-2005 season to the 2006-2007 season. J Infect Dis. 2009;199(2):159-67.

35. Centers for Disease Control and Prevention (CDC). Prevention and Control of Influenza - Recommendations of the Advisory Committee on Immunization Practices (ACIP). MMWR Morb Mortal Wkly Rep. 2005;54(RRo8). p. 1-40. Available from: http://www.cdc.gov/mmwr/preview/mmwrhtml/rr5408a1.htm

36. Klimov AI, Rocha E, Hayden FG, Shult PA, Roumillat LF, Cox NJ. Prolonged shedding of amantadine-resistant influenzae $A$ viruses by immunodeficient patients: detection by polymerase chain reaction-restriction analysis. J Infect Dis. 1995;172(5):1352-5.

37. Martínez-Baz I, Reina G, Martínez-Artola V, Fernández-Alonso $M$, Salcedo E, Mazón A, et al. [Effect of the time between symptom onset, swabbing and testing on the detection of influenza virus]. Enferm Infecc Microbiol Clin. 2012;30(1):11-4.

38. Carrat F, Vergu E, Ferguson NM, Lemaitre M, Cauchemez S, Leach $S$, et al. Time lines of infection and disease in human influenza: a review of volunteer challenge studies. Am J Epidemiol. 2008;167(7):775-85.

39. World Health Organisation (WHO). Recommended composition of influenza virus vaccines for use in the 2012-2013 northern hemisphere influenza season. Geneva: WHO;Feb 2012. Available from: http://www.who.int/influenza/vaccines/virus/ recommendations/201202_recommendation.pdf

40. Yao X, Hamilton RG, Weng N, Xue Q-L, Bream JH, Li H, et al. Frailty is associated with impairment of vaccine-induced antibody response and increase in post-vaccination influenza infection in community-dwelling older adults. Vaccine. 2011;29(31):5015-21.

41. Goodwin K, Viboud C, Simonsen L. Antibody response to influenza vaccination in the elderly: A quantitative review. Vaccine. 2006;24(8):1159-69.

42. Song JY, Cheong HJ, Hwang IS, Choi WS, Jo YM, Park DW, et al. Long-term immunogenicity of influenza vaccine among the elderly: Risk factors for poor immune response and persistence. Vaccine. 2010;28(23):3929-35.

43. McElhaney JE, Effros RB. Immunosenescence: what does it mean to health outcomes in older adults? Curr Opin Immunol. 2009;21(4):418-24. 